\title{
Las abogadas y los abogados: modernas, modernos y coloniales ${ }^{(*)}\left(^{*}\right)$
}

\section{Lawyers: Modern and Colonial}

\author{
César Bazán Seminario ${ }^{(* *)}$ \\ Arnold Bergstraesser Institut
}

Resumen: Siguiendo las líneas de exploración decoloniales, sugiero que las abogadas y los abogados reproducen mediante su actuación patrones de la matriz de colonialidad del poder. Para eso describo en la primera parte de este texto en qué consiste la opción decolonial, mientras que en la segunda parte analizo a las abogadas y los abogados, así como a las facultades de derecho con una mirada atenta a los rasgos de la colonialidad/ modernidad en ellas y ellos. El resultado es que identifico a las abogadas y los abogados como guardianes legales de la colonialidad del poder y a las facultades de derecho como centros de reproducción de la lógica modernidad/colonialidad.

Palabras clave: Sociología del Derecho - Colonialidad - Modernidad - Abogados Matriz de dominación

\begin{abstract}
Following the lines of decolonial thought, I suggest that lawyers reproduce patterns of the matrix of colonial power through their actions. In the first part of this article I describe what the decolonial option is, while in the second part I analyze lawyers and law schools paying close attention to the signs of coloniality/modernity within them. As a result, I identify lawyers as the legal guardinas of colonial power and law schools as places that reproduce the logic of modernity/coloniality.
\end{abstract}

Keywords: Sociology of Law - Coloniality - Modernity - Lawyers - Matrix of domination

$\left.{ }^{*}\right) \quad$ Nota del Editor: este artículo fue recibido el 3 de marzo de y su publicación fue aprobada el 21 de abril de 2019.

${ }^{* *}$ Este texto es un avance de mi tesis doctoral, la cual se encuentra actualmente en elaboración.

${ }^{* * *}$ Abogado, activista e investigador. Doctorando del Instituto de Sociología de la Universidad de Friburgo, ALMA Fellow en el Arnold Bergstraesser Institut, máster en Estudios Latinoamericanos por la Universidad Libre de Berlín y abogado por la Pontificia Universidad Católica del Perú. Miembro del comité directivo de Informationstelle Peru e.V. y exmiembro del comité directivo del Instituto de Defensa Legal. Correo electrónico: 


\section{Introducción}

Académicas y académicos de universidades americanas y europeas han planteado con renovada energía diferentes críticas y propuestas teóricas que, vistas conjuntamente, promueven una mirada macro de las relaciones de poder y dominación de (y en) América Latina con relación al entorno global, mostrando importantes continuidades entre la situación colonial y la actualidad.

Se trata de posturas académicas que hacen explícito su objetivo político, de modo tal que renuncian a falsas pretensiones de neutralidad científica, ya cuestionadas duramente por intelectuales como Bourdieu (2011). Entre los decoloniales, por ejemplo, Catherine Walsh se presenta a sí misma como una intelectual militante, según su página web personal (Walsh 2010), mientras que Castro-Gómez afirma que muchos de los animadores del debate decolonial son profesoras y profesores que viven y trabajan en América Latina y no son académicos de la teaching machine estadounidense (2005, 42-43).

En este artículo, siguiendo las líneas de exploración decoloniales, me pregunto cómo se manifiesta la colonialidad del poder entre las abogadas y los abogados. Para eso, en la primera parte de este texto, describo en qué consiste la opción decolonial, mientras que en la segunda parte analizo a las abogadas y los abogados con una mirada atenta a los rasgos de la colonialidad del poder en ellos. Me centraré en el caso peruano.

\section{Colonialidad y modernidad, dos caras de la misma moneda}

Los diferentes trabajos decoloniales apuntan a denunciar y desmontar la matriz de dominación, calificada por el peruano Aníbal Quijano en reiterados trabajos como la colonialidad del poder (por ejemplo, 1992, 2000, 2007), que operaría en cada uno de los planos de nuestra existencia cotidiana sobre la base de una clasificación racial/étnica y es uno de los elementos constitutivos y específicos del patrón mundial de poder capitalista (Quijano 2007, 93).

La idea de colonialidad del poder implica una cierta continuidad entre la dominación de la época colonial y la dominación en la actualidad. En el caso de América Latina estamos hablando de la persistencia de estructuras y prácticas dominación coloniales ya culminada la colonia, es decir durante el período republicano.

"La globalización en curso es, en primer término, la culminación de un proceso que comenzó con la constitución de América y la del capitalismo colonial/ moderno y eurocentrado como un nuevo patrón de poder mundial. Uno de los ejes fundamentales de ese patrón de poder es la clasificación social de la población mundial sobre la idea de raza, una construcción mental que expresa la experiencia básica de la dominación colonial y que desde entonces permea las dimensiones más importantes del poder mundial, incluyendo su racionalidad específica, el eurocentrismo. Dicho eje tiene, pues, origen y carácter colonial, pero ha probado ser más duradero y estable que el colonialismo en cuya matriz fue establecido. Implica, en consecuencia, un elemento de colonialidad en el patrón de poder hoy mundialmente hegemónico" (Quijano 2000, 122).

Como se puede ver, algunas de las categorías centrales de la colonialidad del poder giran en torno a la dominación sobre la base de la diferencia étnico/racial y el eurocentrismo en el sistema mundo capitalista.

Quijano y Wallerstein postulan que América y el mundo están clasificados en base a categorías étnico raciales, las cuales carecen de ancla genética, no tienen base en una historia antigua y que en momentos de expansión económica se expandían para calzar diferentes grupos en una más elaborada división del trabajo. Por ejemplo en etapas tempranas: esclavitud para los negros africanos, diversas formas de trabajo forzado (repartimiento, mita, peonaje) para los indígenas americanos, enganches para la clase trabajadora europea. Siguiendo con su crítica, ambos reconocen que la etnicidad fue reforzada por el racismo hecho y derecho, teorizado y explícito (1992, 584-585).

En dicha división del trabajo, así como en otros planos de la vida cotidiana, la etnicidad y el racismo encumbraron a ciertas sociedades europeas y norteamericanas y a sus integrantes, promoviendo otra categoría clave para los decoloniales: el eurocentrismo. Desde esa perspectiva, la crítica al eurocentrismo es vital, puesto éste "es una actitud colonial frente al conocimiento, que se articula de forma simultánea con el proceso de las relaciones centro-periferia y las jerarquías étnico/raciales" (Castro-Gómez 
y Grosfoguel 2007, 20). Debido al eurocentrismo, ciertos países de Europa y Norteamérica son sociedades legitimadas, capaces de producir conocimiento considerado válido, mientras que los países de la periferia son receptores de las teorías producidas en el centro.

En esa línea, Said mostró a fines de los setenta como cierto pensamiento dominante europeo construyó una imagen de la diversidad del Otro, bajo la nómina del Orientalismo, a la par que le atribuyó un conjunto de valores y prácticas que se definían como diferentes y ciertamente inferiores a los valores europeos (1979). Un camino similar tomó Coronil, quien exploró prácticas representacionales que muestran a pueblos NoOccidentales como el Otro del Yo Occidental (1996). Como lo resalta Boatcã, Occidentalismo -entendido, siguiendo a Coronil, como la expresión de una relación constitutiva entre las representaciones occidentales de las diferencias culturales y la dominación mundial del Occidente- no es la contraparte del Orientalismo, sino una precondición, un discurso de y sobre el Occidente, que prepara el escenario para lo discursos sobre los Otros No-Occidentales $(2015,82)$.

Ahora bien, el dominio del Norte Global, especialmente de (ciertos países de) Europa y Norteamérica -y la representación de ellos como modelos a seguir- no es sólo epistemológico y científico. Se posiciona en muchos otros campos de la vida cotidiana de la gente. Para demostrar este punto desde una mirada que parte de lo económico, los decoloniales siguen algunos postulados de la teoría de la dependencia, especialmente el referido a la dependencia entre centro y periferia en el desarrollo económico y social de países latinoamericanos (Faletto 2015, 219).

La división del trabajo mundial en base a criterios étnico/raciales de países de centro y periferia puede ser advertida con mayor claridad cuando observamos el mapa de las principales exportaciones de países de América Central, El Caribe y Sudamérica, es decir de países con población étnicamente no europea en el Sur Global. La exportación de países americanos se concentra desde siglos en materias primas. En un sistema económico global que tiene encumbrada la producción de servicios, América Latina está en la periferia del capitalismo mundial. Salvo algunos países, como Brasil, México y otros, la mayoría de países latinoamericanos tuvieron en el 2014 como principal producto de exportación materias primas, léase petróleo, cobre, azúcar, café, plátanos, gas, soya, entre otros.

Gráfico 1:

Mapa de la principal exportación según país, América Central y El Caribe 2014

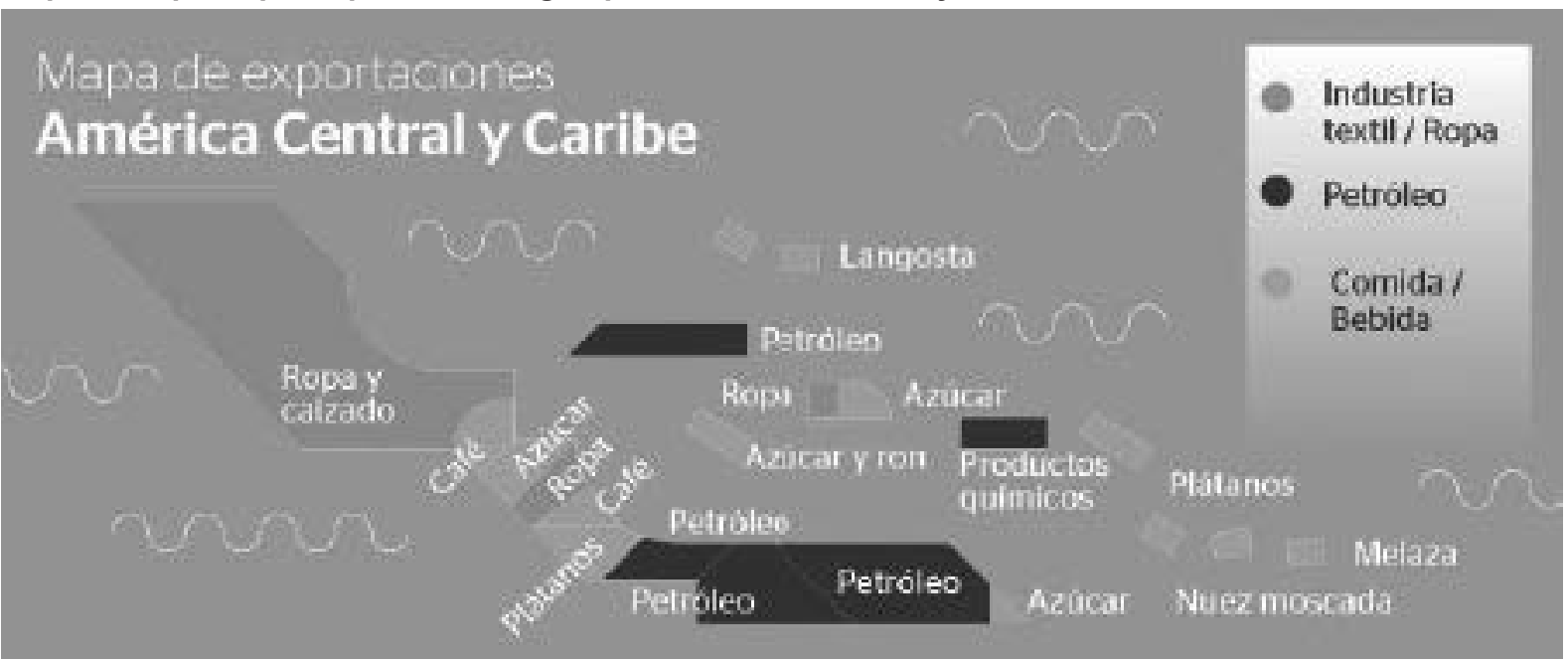

Fuente: BBVA Research (https://www.bbva.com/es/america-latina-rica-materias-primas/) 


\section{Gráfico 2: \\ Mapa de la principal exportación según país, Sudamérica 2014}

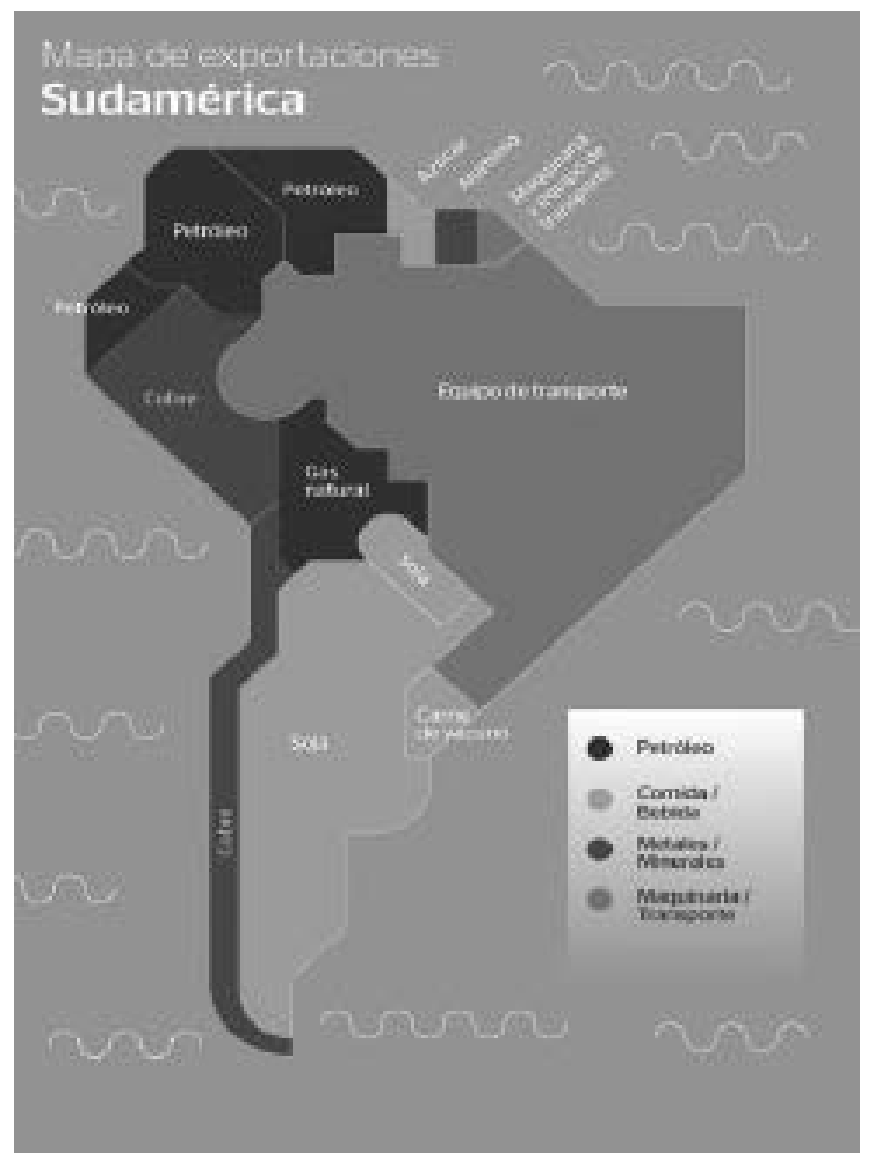

Fuente: BBVA Research (https://www.bbva.com/es/america-latina-rica-materias-primas/)

Para complejizar el asunto hay que considerar que la propuesta analítica centro-periferia apunta a ser replanteada a partir de la desterritorialización del capital, promovida por la globalización económica. Castro-Gómez y Mendieta van en esa dirección al dar cuenta que frente al poder de los estados se ha posicionado el poder de las empresas transnacionales, y que incluso las transnacionales se han convertido "en agentes que afectan los intereses nacionales tanto en los países metropolitanos, como en las zonas anteriormente periferizadas o colonizadas por éstos" $(1998,6)$.

Por otro lado, la potencia de la crítica de Quijano se refuerza cuando se aúna a reflexiones que denuncian otros campos de dominación. Por un lado, Mignolo reconoce que la formación histórica de la matriz colonial del poder en el siglo XVI que tiene como uno de sus puntos principales el género y la sexualidad (2009, 254). En ese sentido, el feminismo y los estudios de género fortalecen la crítica a la matriz colonial.

Por otro lado, la crítica a la matriz colonial es también una crítica a la instrumentalización de la naturaleza al servicio del ser humano, a la depredación de la naturaleza como condición del progreso. Alberto Acosta nos recuerda que la conquista y colonización de América cristalizaron una explotación inmisericorde de los recursos naturales, se fraguó un esquema extractivista de exportación de naturaleza desde las colonias en función de las demandas de acumulación del capital de las metrópolis $(2010,17)$.

Por su parte, Boaventura de Sousa Santos, quien plantea críticas a la opción decolonial, identifica que la dominación mundial es de tres constelaciones entrelazadas: colonial, capitalista y patriarcal (2006, 50-53). Esta dominación se soporta en la constante construcción de líneas abisales $(2017,159)$, que marcan diferencias irremediables entre unos y otros sujetos.

El telón de fondo para la crítica decolonial es la modernidad. De acuerdo a un fascinante libro de Dussel (1994), la modernidad tiene como fecha de nacimiento 1492 y se forja junto con el mito de la modernidad, que involucra al ego europeo, el cual se concibe a sí mismo como centro de la civilización y del desarrollo de la razón, mientras excluye de la historia y ataca violentamente al resto del mundo. La violencia ejercida contra el resto del mundo es justificada por ciertos europeos en tanto se busca que los otros pueblos se incorporen y beneficien de la modernidad, que es a la vez emancipación y utopía ${ }^{(1)}$. La modernidad se nutre entonces de su mito. El mito de la modernidad consiste en "victimar a un inocente (al Otro) declarándolo causa culpable de su propia victimización, y atribuyéndose el sujeto moderno plena inocencia con respecto al acto victimario."

(1) "(Desde el punto de vista del sujeto moderno/colonial) La llamada conquista, en realidad, es un acto emancipatorio, porque permite salir (el Ausgang de Kant) al bárbaro de su "inmadurez", de su barbarie." (Dussel 1994, 72) 
(Dussel 1994, 70). Modernidad y colonialidad son, entonces, dos caras de la misma moneda. La primera no es posible sin la segunda.

En suma, según la opción decolonial persiste en el sistema-mundo una matriz de dominación colonial basada en la diferencia étnico/racial, que se reproduce en lo cotidiano e implica una repartición de los roles de producción tanto a nivel local como mundial, con su centro y periferias. En esa línea, la mirada decolonial critica la instauración de un discurso dominante que coloca a la cabeza de las relaciones de poder al ser humano, especialmente hombre adulto blanco heterosexual y sano, cuyas relaciones con la naturaleza se basan en la instrumentalización de la misma.

Frente a eso, partidarios y partidarias decoloniales tienen propuestas. Aquí quiero resumir dos de ellas. Enrique Dussel plantea no solo la revalorización de modos de pensar distinto, sino que nos motiva a avanzar a lo que él llama transmodernidad. La transmodernidad es un momento próximo de la historia, en el cual la construcción de conocimiento no es eurocéntrico. Las culturas universales, excluidas por el mito de la modernidad, ubicadas en la exterioridad, asumen los desafíos de la modernidad, pero responden desde otro lugar de enunciación, desde el lugar de sus propias experiencias culturales. Ese proceso de creación de conocimiento tiene la capacidad de brindar respuestas inimaginables para el centro

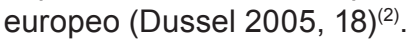

Desde una vereda diferente, Boaventura de Sousa Santos propone respaldar la creación de Epistemologías de Sur (2018), es decir pensar la emancipación desde el Sur para desdibujar las líneas abisales generadas por la dominación capitalista, colonial y patriarcal. Con esa orientación, Araujo apunta a una ecología de los saberes jurídicos o ecología de las justicias (2014), tratando de advertir las ausencias producidas por las ciencias sociales y jurídicas hegemónicas y distanciándose de una metodología extractivista. En su lugar, el conocimiento válido debe ser construido desde las luchas sociales, especialmente de las luchas de la sociedad civil incivil (Santos 2012, 90). En ese sentido, el intelectual no será un intelectual de vanguardia, sino uno de retaguardia, que está al lado de los oprimidos.

Las sugerentes propuestas de Dussel y Santos encuentran paralelos en otros modelos de construcción epistemológica decolonial, como el diálogo intercultural (Walsh 2007) o el delinking (Mignolo 2012, 48-49).

\section{Abogacía y facultades de derecho desde una mirada decolonial}

3.1. Las abogadas y los abogados: guardianes legales de la modernidad/colonialidad En la profesión legal la colonialidad del poder parece latente. Siguiendo la lógica de su cotidianidad, abogados y abogadas reproducirían en sus actuaciones los patrones coloniales, que se desarrollaron con la conquista de América hasta la actualidad, bajo el ego colonizador y sus ideales de salvación, cristianizar, civilizar, traer la razón y el progreso, modernizar, etcétera.

Al contrario de lo que pasaba en las tierras que luego fueron llamadas América, al momento de la conquista la profesión legal estaba bastante extendida en los territorios de los conquistadores europeos. Como reseña Honores, el auge de los abogados se dio con el surgimiento de los Estados modernos europeos en los siglos XV y XVI. Los expertos jurídicos varones fueron asociados a las labores de gobierno y administración judicial, así como al servicio de intereses de particulares (2003a, 431). Pereyra, al reseñar un texto de De Dios, describía de la siguiente manera el rol de los juristas durante la época de los Reyes Católicos, así como su privilegiada posición respecto del poder en la sociedad:

“(...) [los juristas] encontraban un lugar fundamental en las nuevas instituciones de justicia y de gobierno impulsadas por los Reyes Católicos en su afán de fortalecer la monarquía. Representantes de estos participan así en diversos espacios tales como los corregimientos, las Audiencias, las Chancillerías, Ios Consejos (Consejo Real y Cámara de Castilla). Estos letrados acompañan el conjunto de reformas propuestas por la monarquía y se convierten en firmes

(2) Este modelo para comprender el sentido de la transmodernidad es explicado muy didácticamente por Dussel en un seminario en la universidad Andina de Ecuador, utilizando el ejemplo de un científico maya que a partir de conocimientos clave de su cultura y el uso de herramientas de la modernidad, encuentra respuestas sobre los mayas, que la ciencia eurocéntrica no había intuido (Dussel 2009). El registro audiovisual puede ser consultado aquí: https://www.youtube.com/watch?v=gql9yYhdvws (última visita 29 de noviembre de 2017). 
aliados de la misma alcanzando una posición privilegiada y expectable dentro de la sociedad" (Pereyra 2018, 245).

Paralelamente en las tierras del Tawantinsuyo no existían los juristas. La estructura social y estatal de aquella civilización imperial, que había logrado dominar gran parte de los territorios americanos del sur, era ajena a la idea de un grupo de personas de élite, letradas, formadas en centros universitarios en el estudio de las leyes y la jurisprudencia del derecho canónico y el derecho romano, poseedoras de cierto poder jurídico sustentado en la lógica modernidad/colonialidad. Parafraseando a Barrientos diré que no se encontraban en esas tierras a un estamento letrado, conocedor de la literatura jurídica, ocupado en oficios públicos vinculados al consejo del monarca y la jurisdicción real, en servicios al clero y que domina un estilo judicial y notarial $(1999,110)$.

Si bien en el Tawantinsuyo la formación podía hacerse fuera del grupo familiar, no se hacía en universidades, sino en el Yachay Wasi. Szeminski (siguiendo a Guaman Poma de Ayala) no muestra en su listado de funcionarios incaicos alguno que pueda equiparse específicamente a la idea del jurista de los reinos de la Corona de Castilla $(2015,20)$. Sin embargo, debido a que en Europa la profesión del jurista estaba ligada con el ejercicio del poder central, son varios los personajes y linajes que -estirando el concepto- podría considerarse ejercían labores de juristas (Szeminski 2015, 21 - 22). Por ejemplo, el michuq o mich'uq ("observaba lo que pasaba en su jurisdicción y era "juez de tomar cargo y residencia"... los que recibían la función eran los awkikuna") $(2015,21)$.

A pesar de esas semejanzas, es muy difícil, sino impreciso, encontrar coincidencias entre estos actores y linajes del Tawantinsuyo y los juristas europeos. Las principales dificultades son dos. La primera radica en que la lógica modernidad/colonialidad no era propia del Tawantinsuyo ${ }^{(3)}$. La segunda dificultad consiste en que la mirada jurídica al Tawantinsuyo se han construido principalmente a partir de narraciones mediatizadas de personas formadas en una cultura de inspiración romanística, eurocéntrica: "todos los trabajos etno-históricos [sobre el Derecho Precolombino], (sic) son interpretaciones de los testimonios registrados después de la invasión española" (Olivero, 101). Se trató de explicar los hechos del Tawantinsuyo desde la cosmología del colonizador occidental, de los vencedores.

El concepto de jurista llegó a América en los barcos coloniales. Como resulta evidente, dichos conceptos no fueron simplemente imitados, sino que en el traslado e implantación en las tierras conquistadas se produjeron variantes. Danwerth sugiere que las instituciones y normas originarias de Europa se (re)producen en el "Nuevo Mundo" impactadas de alguna manera por las prácticas locales $(2014,326)$. Sin embargo, se advierten ciertas líneas de continuidad relacionadas con la colonialidad del poder.

Desde el inicio de la dominación española, los juristas han tenido un rol central en el ejercicio del poder conquistador y colonial. En cuanto a la conquista, Leiva llega a señalar que en casi todas las expediciones importantes habían no solo soldados y sacerdotes, sino también letrados (2010, 435) $)^{(4)}$.

Por otra parte, un ejemplo temprano de juristas en la colonia fue Polo Ondegardo. De acuerdo a lo reseñado por Danwerth, Polo Ondegardo, nacido en Valladolid y jurista de la Universidad de Salamanca, llegó al Perú en 1544 y fue valorado por virreyes y clérigos hasta su muerte en 1575. A él le encargaron diferentes puestos jurisdiccionales y de gobierno, la elaboración de normas y además fue un destacado hombre de negocios (2014, $327)^{(5)}$. El licenciado Polo Ondegardo no fue el único. Diversos estudios dan cuenta, a lo largo de la colonia, de juristas cercanos al poder moderno/colonial. Tal es el caso del polémico licenciado Juan de Matienzo, oidor de Charcas y asesor de un Virrey del Perú (Leiva 2010) y del licenciado Diego Álvarez de Toledo durante el siglo XVI (Lohmann 1969); del licenciado Tomás Durán, asesor del gobernador de Chile y de un Virrey del Perú (Dougnac 2018) y del obispo Feliciano de Vega, nacido en Lima, rector de la Universidad Nacional Mayor de San Marcos en el siglo XVII (Barrientos 1999); entre otros.

Coincidentemente con su cercanía al poder real, juristas tanto en Europa como en América se adhirieron rápidamente a teorías que consolidaron la pertenencia de las tierras conquistadas a favor de los Reyes Católicos y la aplicación del derecho castellano en

(3) El imperio Inca ejerció su dominación en América sobre la base de una lógica distinta.

(4) Honores precisa que inicialmente: Los abogados y procuradores estaban legalmente impedidos de ingresar a América, pero estas disposiciones fueron prontamente inobservadas. En realidad resultaron contradictorias en sí mismas con el proyecto colonizador que confiaba en el Derecho (de tradición romano-canónica) y en la ley como entes reguladores de la aventura colonial (2003b, 435). 
aquellos territorios. Juan Solórzano y Pereyra y fray Gaspar Villaroel desde el Virreinato del Perú son dos exponentes de esas convenientes teorías jurídicas, desarrolladas anteriormente por juristas de la península ibérica y de Panamá, como Francisco de Avilés, Juan García Gallego, Juan Bautista Valenzuela Velásquez y Francisco Carrasco del Saz (Barrientos 1999, 102-105).

Si bien la dominación moderna/colonial sustentada en el derecho y sus juristas era la regla, se pueden identificar matices y contradicciones. Una de ellas se ejemplifica en Bartolomé de las Casas, sevillano, sacerdote, quien estudió derecho en Salamanca y fue nombrado en 1516 "protector de indios" por el Cardenal Cisneros. De las Casas ha pasado a la historia porque se enfrentó contra la deshumanización de los nativos americanos y defendió la tesis de que los indígenas debían ser tratados adecuadamente. Sin embargo, su lógica se movía dentro de los márgenes de lo moderno/colonial, puesto que defendía la necesidad de un protectorado temporal y de cristianizar (sin violencia) a las personas no occidentales (Beuchot 1993, 5). Asimismo, coherente con su locus de enunciación, la fundamentación filosófica de de Las Casas es de vertiente occidental: la escolástica y el humanismo renacentista (Beuchot 1993, 7-8). Más allá de eso, él fue una figura esencial en la lucha contra la exclusión étnico-racial y en pos de la dignidad de los habitantes originarios de América. Aunque pareciera que no puede decirse lo mismo respecto de su posición sobre los esclavos africanos ${ }^{(6)}$.

Como es sabido, durante la colonia se instauraron dos repúblicas: una de españoles y otra de indios, que contaban con autoridades propias y estaban subordinadas a la Corona española (De Trazegnies 2010,664). A la par había contacto entre ambos regímenes, con claros beneficios para el grupo étnico-racial dominante:

Desde el lado español, hay una proyección sobre el lado indio basada en la necesidad de una administración común al menos a partir de un cierto nivel, el imperativo evangelizador que implica la difusión del cristianismo y la extirpación de idolatrías, la cobranza del tributo indígena, la utilización de mano de obra india. Desde el lado indio, el contacto con el lado español se busca para el desarrollo de actividades comerciales, como el abastecimiento local, la venta y transporte de productos (De Trazegnies 2010, 665).
En el marco de los dos regímenes, nobles indígenas también recurrieron a abogados para que los patrocinen en juicios, como estrategia de defensa relativamente exitosa ante el avasallamiento colonial (Honores 2003b). Entre los abogados de indígenas destacó el licenciado Francisco Falcón, quien en 1567 es nombrado "representante de todos los indios" ante el segundo consejo provincial de Lima (Honores 2003b, 14). Frente esa situación, juristas y autoridades coloniales desarrollaron una estrategia para contrarrestar el poder del litigio indígena. El Virrey Toledo emitió ordenanzas entre 1572 y 1575 para regular las controversias indias y promovió jueces especiales de indios y un sistema público de asesoría y asistencia judicial, que acabó con la red privada de abogados y procuradores para la nobleza indígena (Honores 2003b, 18-20). El sistema iniciado por Toledo se extendió potenciado hasta el final del virreinato.

Esos ejemplos muestran que los juristas coloniales en América estuvieron ligados al poder colonizador. Incluso, aquellos valiosos casos de juristas que apoyaron a los indígenas, subalternizados, fundamentaron su defensa desde la matriz filosófica y jurídica colonial.

Esa misma lógica moderna/colonial del poder legal parece presente también en los juristas de la república, en su expresión eurocéntrica, racista, machista y de dominio de la naturaleza en un sistema mundo capitalista. Es decir, a pesar de haber concluido formalmente la dependencia administrativa respecto de una potencia colonial europea, se mantendría vigente hasta nuestros días la colonialidad del poder en las y los juristas peruanos. En ese sentido, la cercanía de los abogados a la cúspide del poder estatal no fue diferente a inicios de la

(5) Corregidor y Capitán General de Charcas, poseedor de una encomienda en Cochabamba y de una veta de plata en Potosí, posteriormente fue Corregidor en Cusco y consejero del Virrey Toledo. Además, como burócrata fue autor de muchos textos que, sin ser crónicas, guardan información sobre el período colonial y del Tawantinsuyo. Por otra parte, Ondegardo -bajo la lógica del conquistador- recomendó a la corona la aplicación del régimen de fueros para mantener cierta forma de organización indígena, siempre que no colisionara contra los principios de la religión y el derecho natural (Danwerht 2014, 327-329).

(6) Esponera (2010), siguiendo a Pérez, sugiere que el cambio de Bartolomé de las Casas respecto de la esclavitud de negros opera entre 1545 y 1547. Pérez alega que a partir de esas fechas de las Casas deja su desinformada complacencia con la esclavitud de africanos y la reemplaza por una posición crítica. 
república, mientras la carrera de derecho mantenía un estatus elitista.

En el devenir histórico republicano de los abogados en el Perú resulta interesante revisar aquel capítulo de mediados del siglo XIX sobre los intentos de eliminar la defensa cautiva, es decir la obligatoriedad de ser patrocinado por un abogado en un proceso judicial. En ese capítulo se muestra a los abogados como una élite blanca, masculina y citadina, que resiste a la propuesta de eliminar la defensa cautiva, mediante ataques racistas contra el parlamentario autor del proyecto, tildándolo de mulato (Whippie 2016, 136), a la par que se afirma que de aprobarse la defensa libre, desaparecerían los abogados, lo que equivaldrían a „acabar con la ilustración y entronizar el reinado e la ignorancia" (Whippie 2016, 136). Ciertamente, defender la obligatoriedad del abogado en el litigio era defender una gran cuota de poder moderno/colonial, que generaba dependencias clientelares entre abogados, agentes informales y litigantes. La propuesta movilizaba aquellas redes de poder. Sin embargo, el planteamiento legislativo alegaba estar motivado por la falta de abogados en el país y el desinterés de estos por servir fuera de las ciudades (Whippie 2016, 132).

Con el devenir del siglo XX, el crecimiento del número de abogados y abogadas y del aparato estatal, "los abogados se habrían distribuido en toda la estructura del estado" (Pérez Pérdomo 2009, 13). De ese modo, el avance de la república trajo como novedad que las y los juristas tendrían que compartir más su poder en las altas esferas estatales, a la par que expandían su presencia en las oficinas del estado. Durante el siglo XX el número de abogadas y abogados creció sustantivamente. De acuerdo a cifras recopiladas por Bergoglio mientas que en 1950 habían 23 abogadas y abogados por cada 100000 habitantes, en el 2002 habían 250 por cada 100000 habitantes en el Perú $(2007,33)$. De esa manera, "el título de abogado ya no es suficiente para garantizar el acceso a las elites, principalmente políticas" (Bergoglio 2007, 13). Se podría decir entonces que durante el siglo XX el color de la piel de los abogados dejó de ser principalmente blanco y tomó tonalidades del marrón y negro. Además se incorporaron mujeres: el sexo de los juristas también varió.

La exacerbada admiración de los juristas por lo proveniente del Norte Global, sea de países de Europa occidental o de Estados Unidos de América, se mantuvo como constante en la república. Dicho eurocentrismo es graficado por Ramos Nuñez al comentar las reflexiones que plantea un viajero francés sobre su visita al Perú y Bolivia. Sus opiniones se refieren al Código Civil de la Confederación Peruano-Boliviana, similar al Código Civil Napoleónico, encargado de regir la vida de quechuas, aimaras y de otros pueblos bolivianos y peruanos:

"Las reflexiones del viajero francés trasuntan una idea de progreso que era compartida por los extranjeros y por aquellos hijos del país que entonces constituían la élite política y cultural: las legislaciones modernas, bajo la forma de códigos básicos, facilitan el desarrollo y dan libre curso a la prosperidad. El relato ofrece la imagen emblemática de un código moderno en tierras inhóspitas, habitadas mayoritariamente por indígenas. Nada parecía mejor al joven vizconde que adoptar el Code napoleónico, para que así estas tierras alcanzaran un nivel semejante al logrado por su país" (Ramos Nuñez 2005, 33).

La palpable influencia de normas jurídicas del Norte Global en el Sur, como manifestación del eurocentrismo, es un fenómeno común en el Perú. Más aún si en la formación de los abogados se repite acríticamente que el derecho peruano es parte de la tradición jurídica romano-germánica (Rubio 2011, 114). Debido al eurocentrismo, ciertos países de Europa y Norteamérica están legitimados para producir conocimiento jurídico considerado válido, mientras que el Perú, desde su periferia, es receptor de las teorías producidas en el centro.

El eurocentrismo está presente en las diferentes ramas del derecho. Como nos lo recuerda Ramos Nuñez (2018, 11-12), las constituciones peruanas, especialmente las primeras, han tenido una fuerte influencia de la Constitución de Cadiz (1812). En un sentido similar, es decir de dependencia epistemológica del Sur con relación al Norte, Gargarella y Courtis señalan que la mayoría de constituciones latinoamericanas que trascendieron al siglo XX tienen como modelo la constitución de los Estados Unidos de América de 1787, de vertiente liberal y elitista $(2009,20)$.

En el campo penal peruano, el estudio de Hurtado Pozo sugiere que el proyecto de Código Penal de Vidaurre presentado en 1828 al parlamento peruano es tributario de la filosofía francesa liberal, el Código Penal de Santa Cruz estuvo inspirado por el código español de 1822, el Código Penal de 1863 era tributario también de su par español y el Código Penal de 1924 tuvo dos fuentes: en mayor medida Suiza, Italia y Argentina y en menor medida Uruguay, Holanda y Suecia (1979, 13-24). 
En el campo civil esto no es diferente. Ramos Nuñez indica que el primer código civil peruano tuvo entre sus fuentes al derecho castellano y al código civil francés, mientras que el código civil de 1936 era de inspiración alemana y suiza (2011, 43). Por su parte, Roger Merino advierte sobre una entusiasta recepción del derecho estadounidense en el derecho civil peruano de la mano con la expansión económica neoliberal y su ideología jurídica conocida como Análisis Económico del Derecho (2008). Entre los teóricos de derecho procesal civil peruano es palpable la influencia juristas italianos, como por ejemplo Giuseppe Chiovenda, Francesco Carnelutti o Piero Calamandrei. El "itinerario de viaje" del primero desde el Norte Global a América, particularmente a Argentina, ha sido estudiado por Levaggi (2009).

Hurtado Pozo $(1979,15)$ recoge una anotación enviada por el jurista José Simeón Tejada al Parlamento con la remisión del proyecto de Código Penal, en 1859, que grafica la exacerbada admiración al derecho del Norte Global entre los abogados del Sur Global autores de la norma:

"El código español ha servido de una luminosa guía en este trabajo, y la comisión juzga propio de su sinceridad rendirle aquí el homenaje debido, confesando que después de meditados estudios ha creído encontrar en sus disposiciones los más saludables principios y las mejores indicaciones de la ciencia... [y en razón a que] estando las actuales costumbres de los peruanos vaciadas en los moldes imperecederos de las leyes y del idioma de Castilla, no era posible alejar nuestro proyecto de aquellas acertadas disposiciones".

Lo descrito es precisamente el drama de la creación de normas abanderada por juristas en la historia del Perú: el derecho se crea desde una perspectiva eurocéntrica, sin tener en cuenta que el país no encuadra plenamente en categorías analíticas propias de las ciencias del Norte Global. Este evidente desfase es usualmente omitido. Frente a ello, Armando Guevara concatena premisas que deberían forma parte del $A B C$ de cualquier abogado y abogada y que, por el contrario, habitualmente están ausentes del análisis jurídico: no existe el Estado-nación, la respuesta oficial del Estado suele ser negar la compleja diversidad local y la complejidad de la realidad es abrumadora $(2001,11-12)$. Siguiendo su análisis, Guevara considera que en esas circunstancias "no hay condiciones sociales, económicas y culturales para que el derecho estatal opere según sus propios postulados" $(2001,17)$

Por otra parte, el racismo-como contracara del eurocentrismo- se advierte también en la producción de juristas americanos. Ramos Nuñez nos hace notar que el Código Civil de Santa Cruz solo tiene un artículo que atiende al mundo indígena, mientras que el Código Civil de 1852 no cuenta siquiera uno.

"El único artículo del Código Civil confederado que atiende al mundo indígena es el 467, que regula el testamento especial otorgado por los naturales, a quienes se concede el privilegio de testar por palabra o por escrito con la sola presencia de dos testigos vecinos. La realidad rural andina, tan diferente a los moldes trazados en los gabinetes de los letrados, no obtuvo más que un retrato bucólico e indolente. Por su parte, el Código peruano de 1852 no trae una sola norma en que aluda a los indios o a sus usos o costumbres. Semejante conducta, que puede ser tachada como un caso ejemplar de esquizofrenia jurídica -si se atiende a la densidad demográfica aborigen-, solo se explica por las convicciones ideológicas de los legisladores" $(2005,35)$.

Aquellas convicciones ideológicas son precisamente las que se hacen presente al crear derecho, pues como es evidente el derecho no es neutral, sino que refleja las dependencias ideológicas de sus autores y aplicadores dentro de la matriz de colonialidad del poder.

Un ejemplo impresionante del racismo en las normas jurídicas creadas por los juristas peruanos se halla en el Código Penal de 1924. Los artículos 44 y $45^{(7)}$ de dicho código se refieren a las personas no-occidentalizadas como salvajes, indígenas semicivilizados o degradados por el alcoholismo y la

(7) "Artículo 44.- Tratándose de delitos perpetrados por salvajes, los jueces tendrán en cuenta su condición especial, y podrán sustituir las penas penitenciaria y de prisión por la colocación en una colonia penal agrícola, por tiempo indeterminado que no excederá de veinte años.

Cumplidos dos tercios del tiempo que según ley correspondería al delito si hubiere sido cometido por un hombre civilizado, podrá el delincuente obtener libertad condicional si su asimilación a la vida civilizada y su moralidad lo hacen apto para conducirse. En caso contrario, continuará en la colonia hasta que se halle en situación o hasta el vencimiento de los veinte años.

Un reglamento del poder ejecutivo determinará las condiciones de vida de los salvajes colocados en colonia penal, que serán organizados en el propósito de adaptarlos en el menor tiempo posible al medio jurídico del país". 
servidumbre. A la par que autoriza que aquellas personas no cumplan su pena en la cárcel, sino en colonias penales agrícolas. Para más inri, según el artículo 44, los salvajes podrán librarse de la pena si se civilizan. No podría ser más clara la incorporación del mensaje de la modernidad/ colonialidad en la ley penal que rigió hasta 1991 en el Perú: el sujeto indígena alcanza la libertad si se adecúa al modo de vida calificado como civilizado, según parámetros tomados del Norte Global.

El Código Penal de 1991, aprobado por Decreto Legislativo 635, pretendió hacerse cargo de la diferenciación racista de la norma antecesora y la derogó. Sin embargo, en lugar de optar por construir interculturalmente una legislación penal permeable a los valores diversos de la sociedad peruana, mantuvo una perspectiva racista (Meini 2016, 54-55). Los abogados autores del código penal, quizá conscientes de que formaban parte de una narrativa occidentalizada, abrieron la puerta para liberar de responsabilidad a algún indígena que cometiese delito, alegando la existencia de un "error culturalmente condicionado"(8).

El racismo y la exclusión no son privativos del derecho penal. Manuel Marzal califica a la constitución peruana de 1979 como adherida al indigenismo moderno que propugna que las sociedades y culturas indígenas deban integrarse a la sociedad nacional, conservando ciertas particularidades propias como la lengua, vestimenta, arte, formas de organización social, etc. $(1981,109)$. Para arribar a ese convencimiento analiza de qué manera los ideólogos de las principales fuerzas políticas representadas en la asamblea constituyente se adhieren a la meta integracionista (Partido Aprista Peruano, Partido Popular Cristiano y la izquierda marxista) (1981, 110-111).

Años más tarde la constitución de 1993 no plantearía cambios sustanciales al indigenismo moderno integracionista. Las disposiciones a favor de la diversidad cultural (artículos $2.19^{(9)}, 17^{(10)}, 48^{(11)}, 89^{(12)}$ y $\left.149^{(13)}\right)$ no fueron producto de un poder constituyente democrático y pluricultural donde estaban representados los diferentes sectores étnicos de la sociedad. Por el contrario, el Congreso Constituyente Democrático, compuesto por 80 personas, tenía una comisión encargada de proponer el texto constitucional (comisión de constitución), que no tenían entre sus miembros a ningún indígena y solo a dos mujeres.

La discriminación en los procesos constituyentes parece ser la regla en América Latina. Demostrando que las fronteras son efímeras y que en Chile pasan injusticias similares a las del Perú, Grez sugiere que ningún texto constitucional ha sido producido a través de procesos constituyentes, sino que "han sido elaborados y aprobados por pequeñas minorías, en contextos de ciudadanía restringida o como resultado de imposiciones de la fuerza armada" (2009). Por su parte, Noguera y Navas retoman la crítica de que el constituyente ecuatoriano para la constitución del 2008 tuvo una segunda fase muy restringida, en la cual el Ejecutivo y sus juristas expertos absorbieron las propuestas recogidas en el gran despliegue participativo que se hizo en la primera fase, en la que tomaron parte organizaciones indígenas (2016, 80-81).

El silenciamiento de la voz de las organizaciones indígenas en la producción de normas fue precisamente el reclamo de estos colectivos, cuando en el 2008 el gobierno peruano adecuó la legislación nacional a las exigencias del tratado de libre comercio con

\footnotetext{
"Artículo 45.- Tratándose de delitos perpetrados por indígenas semicivilizados o degradados por la servidumbre y el alcoholismo, los jueces tendrán en cuenta su desarrollo mental, su grado de cultural y sus costumbres y procederán a reprimirlos, prudencialmente conforme a las reglas del artículo 90. Podrán asimismo, en estos casos, sustituir las penas de penitenciaría y de relegación por la colocación en una colonia penal agrícola por tiempo indeterminado no mayor que el correspondiente al delito, señalando el plazo especial en que el condenado estará autorizado a obtener libertad condicional con arreglo al título VII. Podrán también reemplazar la pena de prisión según el procedimiento permitido por el artículo 42".

(8) "Artículo 15.- Error de comprensión culturalmente condicionado

El que por su cultura o costumbres comete un hecho punible sin poder comprender el carácter delictuoso de su acto o determinarse de acuerdo a esa comprensión, será eximido de responsabilidad. Cuando por igual razón, esa posibilidad se halla disminuida, se atenuará la pena".

(9) Ese artículo recoge el derecho a la identidad étnica y cultural.

(10) Ese artículo establece el deber estatal de fomentar la educación bilingüe e intercultural y de preservar las manifestaciones culturales y lingüísticas.

(11) En ese artículo se señala que son idiomas oficiales el castellano, quechua, aimara y otras lenguas.

(12) Dicho artículo otorga personería jurídica de las comunidades campesinas y nativas y establece el respeto a su organización autónoma. Además establece que su propiedad es imprescriptible.

(13) Se reconoce que a la justicia de las rondas y comunidades campesinas y de las comunidades nativas.
} 
Estados Unidos de América. Aquella adecuación normativa -en la que activamente participaron abogados y abogadas-estaba compuesta por casi un centenar de decretos supremos y fue calificada críticamente por Merino como el punto más alto del proceso de americanización del derecho peruano $(2008,2)$, a la par que Manacés y Gómez resaltan que el paquete de normas, visto como un conjunto, está orientado a "colocar en el mercado cuanto recurso sea comercializable dentro de un modelo neoliberal extremo" $(2013,46)$.

Entre esas normas, aprobadas sin un proceso participativo de consulta a las organizaciones indígenas, estaba el decreto legislativo 1015 que flexibilizaba las reglas jurídicas para que las comunidades campesinas y nativas de la sierra y selva transfieran su propiedad. El trasfondo de dicha modificación era que la propiedad de las tierras indígenas se aproxime jurídicamente al concepto liberal de propiedad privada. En respuesta, el reclamo social contra la norma fue tan fuerte que el gobierno tuvo que retroceder y la modificó. La violencia racista del derecho derivada de la adecuación normativa al mencionado tratado de libre comercio no cobró vidas en esa oportunidad, pero lo hizo algunos meses después, con ocasión de la gran movilización de los pueblos Awajun, Wampis, Achuar, Yine, Asháninkas, Yaneshas, Shawi, Kichwa, Cocama, Matsés, Machiguenga y de organizaciones indígenas, de la sociedad civil y colonos $^{(14)}$. Tras meses de frustrantes mesas de negociación para que los decretos legislativos sean sometidos a la consulta previa, regulada por el Convenio 169 de la Organización Internacional del Trabajo, el 05 de junio de 2009 , indígenas, colonos y policías se enfrentaron cerca de la ciudad de Bagua, con el resultado de alrededor de una treintena de personas fallecidas.

Ahora bien, la discriminación jurídica no opera solo respecto de aquellos colectivos señalados como indígenas, sino que las y los juristas muestran desinterés para comprender la diversidad en el derecho, a pesar de que esa diversidad no sea ajena, sino próxima. Me refiero a la diversidad jurídica mestiza y urbana ${ }^{(15)}$. Gálvez, que hace un balance de cincuenta años de estudios sobre pluralismo jurídico en el Perú (1964-2013), identifica un grupo pequeño de investigaciones dedicadas a barrios periféricos en la costa central. Lamentablemente el número de trabajos recopilados no llega a diez $(2016,93)^{(16)}$.
Por otra parte, a partir de una toma de conciencia del racismo como un problema social importante en el Perú, se han producido algunas normas que lo combaten. En esa dirección se pueden contar ordenanzas municipales y regionales que prohíben la discriminación, el Código de Protección y Defensa del Consumidor y al Código Penal. Sin embargo, sobre el control penal al racismo, Wilfredo Ardito sostuvo no hay denuncias ni condenas por ese delito (entrevista, 06 de febrero, 2019). Asimismo, Ardito consideró que el racismo indirecto del derecho se manifiesta, por ejemplo, en la emisión de normas en castellano y no en los otros idiomas hablados en el país.

El derecho no solo está impregnado por el racismo, sino también por el machismo. Como lo recuerda Mantilla, la perspectiva de género nos permite identificar el impacto diferenciado de normas jurídicas sobre las personas, para evitar la discriminación y exclusión $(2013,133)$. En el caso peruano, la discriminación machista del derecho es palpable, considerando la condición patriarcal de la sociedad.

En ese sentido, no extraña -como me lo hizo notar Fernando Del Mastro (comunicación personal, 20 de agosto de 2018) - que las comisiones para reformar los códigos civiles y procesales civiles estén compuestas casi exclusivamente por varones ${ }^{(17)}$. Por otra parte, Rocío Villanueva sugiere que a lo largo de la historia republicana el sistema jurídico no ha respetado la autonomía de las mujeres y que ellas han sido objeto de normas legales que han dificultado o impedido que sean dueñas de su destino $(1997,488)$. Villanueva explora la legislación peruana desde la perspectiva de género y encuentra normas que directamente refuerzan roles y modelos

(14) He elaborado este listado a partir de la narración de Manacés y Gómez 2013, 70.

(15) Quizá sea interesante graficar este asunto con la pregunta ¿cómo funciona el derecho a pocas cuadras (o incluso dentro) del Palacio de Justicia en Lima?. Esta pregunta contrasta con otra formulada reiteradamente por Juan Carlos Ruiz Molleda: ¿qué pasa con el derecho a 3.300 m.s.n.m?, que fue recogida por Armando Guevara en el año 2014.

(16) Los trabajos citados por Aníbal Gálvez (2016: 93) se agrupan entorno a dos ejes: 1. Administración de justicia en conflictos por lotes: Desco 1977, Iturregui y Price 1982, Arce 1990, Revilla y Price 1992, y Calderón 1993; 2. Protección frente a la delincuencia: De Soto 1989 y Castillo 1993.

(17) Tal como fue publicado en El Peruano, en octubre de 2016 se conformó una comisión de expertos para reformar el código civil y otra para reformar el código penal. El Ministerio de Justicia convocó a dieciséis personas para conformar estas comisiones. Solo una de ellas era mujer. En: https://elperuano.pe/noticia-ministerio-justicia-convoca-a-juristas-para-revisar-codigos-47626.aspx. Última consulta: 4 de febrero de 2019. 
de virtud personal(18) y otras que lo hacen indirectamente ${ }^{(19)}$ (1997, 489-491).

En cuanto a la concepción moderna/colonial del hombre como encargado de dominar y transformar la naturaleza, se puede decir que el derecho ha hecho eco de esta propuesta. Basta argumentar que en el derecho peruano son sujetos de derechos solo los seres humanos o ellos como colectivos (empresas, sociedad de gananciales o el Estado). A pesar de que en países vecinos como Ecuador y Bolivia hay un fuerte debate sobre la naturaleza como sujeto de derechos, en el Perú dicha idea no ha penetrado en la concepción moderna/colonial imperante. La lógica de que la naturaleza sea sujeto de derechos rompe con la idea moderna de que el ser humano es el centro de la naturaleza y le obliga a compartir esa posición jurídica con otros seres. Siguiendo la lógica colonial/moderna, en el Perú las normas de derecho ambiental tienen como central el derecho a un medioambiente sano y equilibrado, del cual el ser humano es titular.

Las relaciones entre capitalismo y derecho -referidas en diferentes partes de este capítulo- resultan más evidentes si se abordan desde dos situaciones emblemáticas, como la neoliberalización de los años noventa y las prácticas del siglo $\mathrm{XXI}$ que cuestionan la lógica extractiva capitalista.

La neoliberalización producida en los años noventa en el Perú necesitó de las abogadas y los abogados. La teoría y práctica de juristas cumplió un papel fundamental en la legitimación del proyecto neoliberal, que enfatizó en la cultura jurídica nacional la opción preferencial por garantizar el libre mercado, los derechos de propiedad y los contratos, a la par que restó importancia a la desigualdad y la exclusión social (Gonzáles 2015, 76): "Ios grandes estudios de abogados buscaron optimizar sus servicios para lograr que el ordenamiento legal sirviera a los fines de las reformas económicas" (Gonzáles 2015, 76).

Sobre el segundo tema, Saldaña y Portocarrero afirman que el derecho en el Perú es violento contra las personas que participan de protestas sociales, puesto que se autoriza la violación de los derechos humanos de los manifestantes (2017, 314), ya que ellos desafían la autoridad del Estado al cuestionar el modelo económico extractivo $(2017,315)$. La violencia del derecho contra manifestantes opera legalmente a través de la ampliación de supuestos para la intervención de las fuerzas armadas en temas de orden público (Decreto Legislativo $1095^{(20)}$ ), opta por la impunidad vía la llamada ley de licencia para matar ${ }^{(21)}$, los convenios remunerados entre la policía y las empresas mineras y la flexibilización de estándares vía normas policiales internas, y finalmente se radicaliza por la participación en conflictos sociales de unidades policiales antiterroristas (Saldaña y Portocarrero 2017, 320-328).

Adicionalmente, tal como sugieren estos autores, la violencia del derecho en defensa del capitalismo toma partido por el uso excesivo de la figura de los estado de emergencia, el endurecimiento de las leyes penales relativas al orden público durante el boom económico (2001 al 2014) y la flexibilización de las garantías del debido proceso penal (2017, 329-340). Por otra parte, la ideología neoliberal en el derecho y en sus cultores jurídicos se hizo presente en el debate sobre las medidas cautelares, generando restricciones para que comunidades, líderes, ambientalistas o cualquier otro colectivo pudiera frenar ciertos proyectos de inversión aun cuando sea inminente y real la violación de derechos fundamentales (Bazán 2011).

En las líneas anteriores he tratado de demostrar que la lógica modernidad/ colonialidad se verifica en el ejercicio del poder entre las y los abogados y he corroborado la potencia explicativa de una mirada atenta a la colonialidad del poder. Sin embargo, al hacer este ejercicio he visto también que la mirada decolonial resulta poco atenta a otros temas propios del ejercicio del poder de los abogados y abogadas, como la corrupción. La corrupción de los abogados es un tema que ha sido tratado en diferentes diagnósticos y planes de reforma de la justicia. Por ejemplo, el Plan Nacional de la Comisión Especial para la Reforma Integral de la Administración de Justicia identificó como posibles vías mediante los cuales los abogados corrompen las siguientes: "(i) estudios o bufetes vinculados a jueces y auxiliares de justicia, (ii) jueces que patrocinan por interpósita persona" (CERIAJUS 2003, 50).

(18) "Artículo 546 del código penal de 1863.- La mujer que cometa adulterio perderá todos los derechos de la sociedad conyugal, y sufrirá una reclusión por el tiempo que quiera el marido, con tal que no pase de seis meses".

(19) "Artículo 201 del código penal de 1924.- Será reprimido con prisión no mayor de dos años, el que sedujera y tuviere el acto carnal con una joven de conducta irreprochable de más de catorce años y menos de dieciocho".

(20) Decreto legislativo que establece reglas de empleo de uso de la fuerza por parte de las fuerzas armadas en el territorio nacional.

(21) Ley 30151. Un análisis de la ley puede encontrarse en Bazán 2014. 
Por su parte, Pásara aborda las representaciones sobre la corrupción de los abogados de Lima en la literatura y también lo hace a partir de grupos focales con magistrados y abogados, entrevistas a presos y encuestas de opinión (2005, 74-79) y constata cuantitativamente la ineficiencia control ético disciplinario del Colegio de Abogados de Lima (2005, 83). La Defensoría del Pueblo señala que la corrupción de los jueces solo es posible por la acción de otros involucrados, como los abogados y cuestiona el impacto de los cursos de ética en las facultades de derecho, así como los controles de los colegios de abogados (2006, 78-79). Con mayor detalle, las prácticas de corrupción de abogados han sido estudiadas etnográficamente por Mujica (2011) y Quiñones (2018). Más allá del uso corrupto del derecho, organizaciones criminales utilizan su conocimiento experto del derecho y del funcionamiento del sistema de justicia para cometer delitos. Se trata del uso criminal del derecho.

\subsection{Facultades de derecho: centros de reproducción de la lógica modernidad/colonialidad}

Luego de observar el panorama descrito sobre la abogacía, no extraña entonces que la modernidad/colonialidad, tan inserta en las prácticas y leyes producidas por juristas peruanas y peruanos, se reproduzca como regla en las facultades de derecho.

Tanto durante la colonia como a inicios de la república, las facultades de derecho fueron centros de élites masculinas, de acceso severamente restringido para la mayoría de la población. Durante el siglo XX y XXI la situación varió. Las facultades de derecho en el Perú han pasado por un proceso de apertura, de la mano de la liberalización del mercado de la enseñanza universitaria, que tuvo su cenit en los años noventa con leyes que incentivaron la creación de universidades empresa.

De acuerdo a data del INEI, entre 1996 y el 2010 las universidades públicas y privadas aumentaron hasta llegar a 100, mientras que la población universitaria de alumnos de pregrado creció en más de $130 \%$. En cuanto a derecho, mientras que en 1996 la carrera contaba con 29000 estudiantes, iniciada la segunda década del 2000 el número aumentó en $140 \%$, es decir derecho contaba con un estudiantado compuesto por 70861 personas (INEI 2010). Es interesante también identificar que se alcanzó una relativa paridad de hombres y mujeres entre estudiantes de la carrera (Pásara 2004, 44).

Bergoglio apunta que en la mayoría de países de América Latina, la expansión de la educación superior ha aumentado la cantidad de abogados y abogadas y ha hecho más variada su composición social, en términos de clase, género y etnia (2007, 10). Sin embargo, hay que tomar en cuenta también opiniones contrarias, que discuten, a partir de cifras colombianas, que se haya producido una deselitización de la universidad, en la medida que en 1999 solo el $14 \%$ del total de jóvenes entre 18 y 24 años eran alumnas y alumnos de pregrado y que el $66 \%$ de las y los estudiante de educación superior provenían de los tres estratos más altos de la sociedad (Montoya 2011, 32).

Ahora bien, en el contexto de relativa apertura y de avance de la república no ha habido una reflexión sobre la colonialidad del poder en las facultades de derecho peruanas. Salvo un estudio de Garay es difícil encontrar lecturas decoloniales sobre esta materia. Garay, focalizándose en la enseñanza del derecho constitucional, sugiere que hay un problema de conocimiento sesgado, en detrimento de la formación de pensamiento crítico, puesto que el constitucionalismo que se enseña está impregnado de eurocentrismo, racismo, clasismo y sexismo $(2016,85)$. Frente a ello, un camino para saldar el problema sería incorporar las contribuciones del pensamiento decolonial a la enseñanza del constitucionalismo (Garay 2016, 91-99).

La falta de cuestionamientos al poder colonial/moderno en las facultades de derecho es coherente con lo que nos dijo Ardito:

"La gente percibe al derecho como un mecanismo de poder y ascenso social. Entonces como mucha gente se mete al derecho para eso, lo que menos quiere es entrar a un espacio que cuestione el poder. Más bien, saben que están ejerciendo el derecho para eso, ¿no? Entonces es como una contradicción. Sí hay gente que busca usar el derecho para tener prestigio para ganar dinero, para tener poder, para dominar a otros. Por eso lo que menos le interesa es preocuparse si el derecho tiene ese componente. Hay que ser realistas de cuál es el sentido que tienen los estudios de derecho para muchas personas". (Entrevista, 6 de febrero de 2019).

Para aportar a saldar el déficit de análisis decoloniales de la educación legal, revisaré los planes de estudio difundidos en el 2017 en las páginas web de dos facultades de derecho peruanas ${ }^{(22)}$, buscando rasgos de la

(22) La elección de las facultades se debió a que son dos universidades importantes, con características contrastables: universidad pública versus universidad privada y universidad fundada en la colonia versus universidad fundada durante la ola neoliberal de 
colonialidad del poder: por un lado, la Universidad Nacional San Antonio Abad del Cusco (UNSAAC) (23) fundada durante la colonia hace tres siglos en la ciudad de Cusco y por otro la privada Universidad Peruana de Ciencias Aplicadas (UPC) ${ }^{(24)}$, que empezó a operar en Lima hace tres décadas, mientras en el Perú se implementaban las reformas neoliberales del consenso de Washington.

A pesar de que la educación superior pública transita por una larga crisis, la UNSAAC es aún una universidad prestigiosa y de notable importancia. La carrera de derecho, ubicada en la Facultad de Derecho y Ciencias Sociales, tiene una duración oficial de doce semestres. Después de dos semestres de estudios generales, los estudiantes pueden cursar lecciones de derecho. La estructura del currículo mantiene la antigua división de cuño eurocéntrico, entre derecho civil y derecho penal, presente en la tradición jurídica romano germánica, aunque la matiza con la incorporación de cursos de derecho constitucional y teoría del Estado. En esa lógica eurocéntrica no puede faltar el curso de derecho romano.

En el currículo de la UNSAAC se encuentran además varios cursos relativos a derecho empresarial, como derecho comercial I y II, derechos de autor y del consumidor, derecho de la empresa, derecho financiero, derecho bancario y bursátil, etc. Esta preferencia por materias jurídicas relacionadas con el funcionamiento del mercado, muestran que la formación jurídica está estrechamente vinculada con la economía y particularmente con aquella orientada dentro del sistema capitalista. Es interesante ver el peso de la interdisciplinariedad en la carrera de derecho, en particular aquella que ayudaría a generar pensamiento crítico. Salvo los primeros semestres de estudios generales, en el plan de estudios de la UNSAAC no se encuentra diversidad de cursos de otras disciplinas, que puedan ayudar a la alumna o alumno a profundizar su conocimiento crítico sobre las complejas relaciones sociales peruanas. Los pocos cursos que podrían servir para ello son contados con los dedos de las manos. Por ejemplo, el curso obligatorio Historia del derecho peruano o los electivos Quechua, Historia de las ideas políticas, Sociología jurídica y política o el seminario sobre realidad política nacional.

Por otra parte, la privada UPC tiene una clara adhesión a la ideología neoliberal. Según su propia descripción, la carrera, que dura diez semestres, se focaliza no solo en el derecho sino también en la economía, finanzas y gerencia ${ }^{(25)}$. De esa manera, muchos cursos, de hecho más que en la UNSAAC, están en la línea de economía y derecho de la empresa, como por ejemplo, economía política, micro economía, fundamentos del derecho de los contratos I y II, fundamentos gerenciales, etc. El título de los cursos sugiere que algunos contenidos podrían tener una perspectiva crítica que ayude a las y los estudiantes a ampliar su visión del mundo, como por ejemplo historia de la sociedad y del derecho, ética, filosofía, etc. Evidentemente se trata de pocos cursos, que no balancean la tendencia neoliberal del plan de estudio.

A partir de los planes de estudio tanto la centenaria universidad pública UNSAAC de Cusco y la joven y privada UPC de Lima parecen adherirse a una tendencia a formar juristas funcionales al sistema capitalista

los noventa. Además, en esas facultades se formaron dos abogados relacionados a los casos derivados de la protesta contra Las Bambas en setiembre de 2015, que estudio en mi tesis de doctorado.

(23) El análisis del plan de estudios fue hecho en setiembre de 2017 y revisado en enero de 2019. El plan de estudios de derecho de la UNSAACC fue modificado en agosto 2018, mediante Resolución No. CU-0369-2018-UNSAAC, para adecuarse a la ley universitaria. El plan reformulado se puede ver aquí: http://dr.unsaac.edu.pe/home/ (última consulta 30 de enero de 2019).

(24) El análisis del plan de estudios fue hecho en setiembre de 2017 y revisado en enero de 2019. El plan de estudios de derecho de la UPC se puede ver aquí: https://pregrado.upc.edu.pe/carrera-de-derecho/malla-curricular/malla-derecho-20172.pdf (última consulta 30 de enero de 2019).

(25) La retórica de la presentación de la carrera hace explícita su opción pro empresarial y su adhesión a los valores capitalistas de la modernidad/colonialidad. Bajo el título Conviértete en un defensor de la justicia con visión gerencial, la universidad explica lo siguiente:

La carrera de Derecho de la UPC te ofrece una formación multidisciplinaria, orientada no solo al derecho, si no (sic) también a pensar de una manera distinta con enfoque en economía, finanzas y gerencia. De esta manera serás capaz de entender la realidad y las necesidades de una organización y negociar todo tipo de transacciones con clientes.

Se facilitará una formación jurídica interdisciplinaria e internacional que te preparará para la economía global. Además, tendrás un gran dominio de los contenidos clásicos y modernos del derecho, así como de mecanismos alternativos de resolución de conflictos y de las habilidades de negociación. Tu preparación estará a cargo de prestigiosos y reconocidos profesionales, quienes te guiarán en la adquisición de las competencias para la prevención, conciliación y solución de situaciones legales de toda índole, especialmente del plano corporativo. Asimismo, podrás desenvolverte en los diferentes campos de acción que la economía globalizada exige a los abogados de hoy. (En: https://pregrado.upc.edu.pe/facultad-de-derecho/derecho/. Última consulta: 30 de enero de 2019). 
colonial/moderno. Ambas facultades de derecho muestran pocos cursos que aporten a un entendimiento crítico de la sociedad peruana y menos aún que sumen a una lectura de la colonialidad del poder en el derecho.

Más allá del caso de estas dos universidades, el racismo está presente en la educación jurídica. Según Wilfredo Ardito (entrevista, 6 de febrero de 2019) en las facultades de derecho se naturaliza el racismo por omisiones y acciones de autoridades, docentes y estudiantes. Al ser el racismo un gran problema social, que está por todos lados, las facultades de derecho lo refuerzan al no abordar el tema o negarlo. Según Ardito, en las facultades de derecho se dan prácticas racistas como asociar a las personas blancas como una mejor preparación jurídica, utilizar expresiones racistas y burlas contra profesores o alumnos por sus rasgos andinos. Frente a esa lectura, resulta meritorio que algunas facultades de derecho hayan incorporado en su plan de estudios cursos de racismo y derecho, derechos de pueblos indígenas o de pluralismo jurídico, en los que se abordan saberes jurídicos distintos al eurocéntrico. Me refiero a universidades principalmente de Lima, Cajamarca y Puno.

Por otro lado, las investigaciones sobre enseñanza del derecho en el Perú han anotado otros temas relevantes. Como por ejemplo la calidad de la formación. Luis Pásara ha indagado este tema a nivel nacional en el 2004 y halló que: no había una carrera docente debidamente estructurada, solo uno de cada cinco profesoras y profesores se dedicaba a tiempo completo a la docencia, dos tercios de facultades no contaban con ningún o ninguna docente que tuviera el grado de doctor y que además una proporción considerable de las y los profesores enfrentan una severa limitación pedagógica constatada con la pregunta ¿cómo prepara su clase? y la observación de clases (2004, 37-43).

Además, Pásara sugiere que la enseñanza del derecho en el Perú suele centrarse en el conocimiento de las leyes mediante un método expositivo (de clase magistral), relegando enfoques que relacionen derecho y realidad, así como la solución de problemas sobre la base del razonamiento jurídico $(2004,51-$ 58). Este diagnóstico parece ser compartido con universidades del Norte Global, tal como sugiere Pérez Lledó para España (2007, 90-99) y Hagino para Coimbra (2012, 183-189).

Por otro lado, la calidad de las y los estudiantes no es ideal. En una universidad privada de prestigio, una comisión de profesores advirtió sobre las carencias académicas de los estudiantes que buscaban titularse de abogados. Estas oscilaban entre la falta de preparación jurídica rigurosa y de capacidad expositiva y argumentativa y las dificultades para relacionar conocimientos de diferentes especialidades jurídicas
(Comisión para evaluar los exámenes para licenciatura en Derecho 2008). Corresponde indicar además que desde los noventa, con la liberalización del mercado, se instauró el bachillerato automático por ley, de modo que la y el estudiante que culminó los estudios no requiere escribir una tesina para acceder al grado.

La educación universitaria ha sido evaluada incluso por el Tribunal Constitucional peruano, el cual consideró críticamente que ese estamento se encuentra bajo un estado de cosas inconstitucional(26). Ante esa situación se desplegaron en el Perú una serie de medidas relativas a la institucionalización de las universidades peruanas, como la ley universitaria 30220 y el reemplazo de la Asamblea Nacional de Rectores por la Superintendencia Nacional de Educación Universitaria.

En ese contexto, quizá no resulte extraño que las facultades de derecho hayan aportado poco a comprender temas centrales de la realidad peruana, como los conflictos sociales, la mayoría de los cuales son conflictos socioambientales. Estos conflictos son espacios privilegiados para advertir cómo funciona la colonialidad del poder, puesto que en ellos participan empresas que aportan materia prima para la economía global, operando en zonas rurales del país, muchas veces con población considerada indígena.

La Red de Universidades para la Prevención de Conflictos ha identificado solamente 102 investigaciones sobre conflictos sociales producidas entre el 2000 y 2016 , de las cuales el $57 \%$ fueron hechas en universidades. Del total de investigaciones, el $6 \%$ son de derecho $(2017,27-29)$. Tan dramático como los números anteriores resulta que del universo de investigaciones identificadas, solo $22 \%$ incorporaron la variable intercultural y muchas menos, el $8 \%$, la variable de género (Red de Universidades para la Prevención de Conflictos 2017, 31). Por otra parte, en dicho estudio se identificó diecisiete cursos relacionados a conflictos sociales en programas de pregrado en

(26) STC No. 00017-2008-PI/TC, fundamento jurídico 217. 
universidades peruanas, de los cuales seis estaban en facultades de derecho (2017, 82-84).

El análisis cuantitativo mostrado parece confirmar la hipótesis de que una educación jurídica descontextualizada e irrelevante frente a las necesidades más acuciantes de la región dificulta el surgimiento de iniciativas que aporten a la solución de problemas sociales en América Latina (Montoya 2011).

El panorama puede ser más grave aún. De acuerdo a un texto muy sugerente de Del Mastro (2018) la enseñanza del derecho, a través de su currículo oculto, aviva la hybris, como fuerza opuesta a la justicia y conducente a la perversión, dominación y discordia. Él refiere que el positivismo desvió la atención de lo anímico en el derecho y que esa negación es perjudicial para una formación ética que promueva la justicia (2018, 481-483). Profundizando su crítica, Del Mastro sostiene tres tesis relacionadas con la perversión, la dominación y la discordia difundidas a través de la educación jurídica en el Perú:

- "la enseñanza del derecho forma en el uso de un saber ilimitado al servicio del ego que busca reconocimiento, y no en una profesión que tenga un sentido asociado a la justicia y unos límites claros en su práctica" $(2018,486)$.

- "la enseñanza del derecho forma la capacidad, acrítica, de desenvolverse en entornos injustos, sufriendo o reproduciendo sus desequilibrios, y no desarrolla el interés ni la capacidad para corregirlos en la propia experiencia y en el entorno" $(2018,492)$.

- "los estudiantes son inclinados hacia la discordia cuando se forman en la idea del éxito a través de la derrota del otro, y no es una profesión que los conduzca a generar armonía entre quienes se oponen" $(2018,499)$.

A pesar de esta descripción desalentadora hay experiencias interesantes de enseñanza del derecho a partir su proyección en la sociedad, bajo la lógica del derecho como herramienta de cambio social. Entre esas experiencias peruanas destacaban el curso Proyección Social del Derecho (Zuta y otros 2014) y las clínicas jurídicas (Gonzáles 1999).

\section{Palabras finales: desmontar la matriz de dominación colonial/ moderna}

A lo largo de este artículo he sugerido que los abogados reproducen la lógica modernidad/colonialidad. Llegados al Sur Global en los barcos coloniales, resguardaron con su conocimiento y práctica jurídica el poder de la metrópoli sobre las tierras conquistadas. Desde su posición de poder fueron los blancos varones que fungían de guardianes legales del poder colonial.

Con el paso del tiempo y la llegada de la república, el color de la piel y el sexo de los abogados varió, a la par que tuvieron que compartir su poder en la cúspide y difuminarlo en las oficinas estatales. Su nuevo color de piel marrón no fue óbice para que las abogadas y los abogados siguieran siendo guardianes legales de la colonialidad del poder. Mediante sus prácticas, las abogadas y los abogados refuerzan valores relacionados con el eurocentrismo, racismo, machismo y la concepción de estar encargados de dominar a la naturaleza en medio del capitalismo mundial de la modernidad/colonialidad. Esas mismas prácticas se reproducen en la formación que las y los estudiantes reciben en las facultades de derecho. En conclusión, los rasgos de la colonialidad del poder son visibles en las abogadas y los abogados.

Son precisamente esas y esos juristas de ideología moderna/colonial los que se encargarán de crear derecho y posteriormente aplicarlo. En ese sentido, la dependencia de los abogados y la parcialidad del derecho han sido puestos en evidencia en este artículo. $\mathrm{Ni}$ los juristas ni el derecho son independientes.

Por otra parte, el análisis decolonial no basta nuevamente para entender el ejercicio del poder de las y los abogados de piel marrón en la periferia de un mundo moderno/colonial. Si bien capacidad explicativa de la opción decolonial es válida y útil para evidenciar problemas estructurales, hay temas que son dejados fuera del análisis y que también son relevantes.

Frente a ese panorama estamos llamados comprender nuestro lugar en la historia y apuntar a desmontar la matriz de dominación colonial/moderna de la cual las abogadas y los abogados somos guardianes legales y las facultades de derecho centros de reproducción. Denunciar, evidenciar y principalmente transformar son parte de la agenda decolonial que busca construir un mundo distinto, donde las y los abogados seamos actores de la justicia y no lo contrario.

\section{Referencia Bibliográfica}

Acosta, Alberto. 2010. El Buen Vivir en el camino del post-desarrollo. Una lectura desde la Constitución de Montecristi. Fundación Friedrich Ebert, FES-ILDIS, Quito. 
Araujo, Sara Domingues. 2014. Ecologia de justiças a Sul e a Norte. Cartografias comparadas das justiças comunitárias em Maputo e Lisboa. Tesis de doctorado en derecho, justicia y ciudadanía en el siglo XXI, presentada en la Facultad de Economía de la Universidad de Coimbra para la obtención del grado de doctora. Universidad de Coimbra.

Barrientos Grandón, Javier. 1999. "Un canonista peruano del siglo XVII: Feliciano de Vega (1580-1640)". En Revista Chilena de Historia del Derecho, número 18: 101-118.

Bazán Seminario, César. 2011. "La crisis de las medidas cautelares en el proceso de amparo". En Gaceta Constitucional, número 38, febrero: 83-96.

2014. Con licencia para matar. Análisis de la Ley No. 30151 que modifica el artículo 20 inciso 11 del Código Penal para exonerar de responsabilidad penal a policías y militares que causen lesiones o muerte, en cumplimiento de sus funciones. Documento de trabajo. Lima: Instituto de Defensa Legal. En: https://seguridadidl.org.pe/sites/default/files/Con\%20 licencia\%20para\%20matar.\%20IDL-SC.\%20Enero\%202014.. pdf (última consulta 09 de febrero de 2019).

Bergoglio, María Inés. 2007. Cambios en la profesión jurídica en América Latina. En: Academia. Revista sobre enseñanza del Derecho, 5, 10: 9-34.

Beuchot, Mauricio. 1993. El fundamento de los derechos humanos en Bartolomé de las Casas. En: Arete. V, 1-2: 4-13.

Boatcã, Manuela. 2015. Global Inequalities beyond Occidentalism. Serie Global Connectios. Farmham: Ashgate.

Bourdieau, Pierre. 2011. El campo científico. En: Bourdieau, Pierre. Intelectuales, política y poder, primera edición, octava reimpresión. Eudeba: Buenos Aires.

Castro-Gómez, Santiago. 2005. La poscolonialidad explicada a los niños. Popayán: Editorial Universidad del Cauca, Instituto Pensar.

Castro-Gómez, Santiago y Grosfoguel, Ramón. 2007. Prólogo. Giro decolonial, teoría crítica y pensamiento heterárquico. En: Santiago Castro-Gómez y Ramón Grosfoguel (editores). El giro decolonial. Reflexiones para una diversidad epistémica más allá del capitalismo global. Bogotá: Siglo del Hombre Editores, Universidad Central, Instituto de Estudios Sociales Contemporáneos y Pontificia Universidad Javeriana, Instituto Pensar: 9-23.

Castro-Gómez, Santiago y Mendieta, Eduardo. 1998. Introducción: la translocalización discursiva de Latinoamérica en tiempos de la globalización. En: Teorías sin disciplina (latinoamericanismo, poscolonialidad y globalización en debate). México. Miguel Ángel Porrúa: 3-25.

Comisión Especial Para La Reforma Integral De La Administración De Justicia (CERIAJUS). 2003. Plan Nacional para Reforma Integral de la Administación de Justicia. Lima: CERIAJUS.

Coronil, Fernando. 1996. Beyond Occidentalism: toward Nonimperial Geohistorical Categories. En: Cultural Anthropology, 11, 1: 51-87.

Danwerth, Otto. 2014. Von den Inka lernen, heisst herrschen lernen. Zu zwei Editionen von Schriften eines spanischen Juristen im frühkolonialen Peru. En: Zeitschrift des Max-Planck-Instituts für europäische Rechtsgeschichte. 22: 326-331.

De Trazegnies Granda, Fernando. 2010. La nobleza incaica en el derecho indiano. En: Revista Chilena de Historia del Derecho. 22. Tomo I: 661-685.

Del Mastro Puccio, Fernando. Venga a nosotros tu reino: la justicia como fuerza anímica ausente en la enseñanza del derecho. En: Derecho PUCP, 81: 463-510.

Defensoría Del Pueblo. 2006. Informe Defensorial 109. Propuestas básicas de la Defensoría del Pueblo para la reforma de la justicia en el Perú. Generando consenso sobre qué se debe reformar, quiénes se encargarán de hacerlo y cómo lo harán. Lima: Defensoría del Pueblo.

Dougnac Rodríguez, Antonio. 2018. La barroca cultura jurídica del licenciado Tomás Durán, asesor del Gobernador de Chile y Virrey del Perú José Antonio Manso de Velasco, Conde de Superunda. En: Revista Chilena de Historia del Derecho, 25, 20172018: 15-127.

Dussel, Enrique. 1994. 1492: el encubrimiento del otro: hacia el origen del mito de la modernidad. La Paz: Plural editores, Facultad de Humanidades y Ciencias de la Educación, Universidad Mayor de San Andrés.

2005. Transmodernidad e interculturalidad (Interpretación desde la Filosofía de la Liberación). En: http://enriquedussel.com/txt/ TR A N S M O DER N I D A D \% 20 e \% 20 interculturalidad.pdf (última visita 02 de agosto de 2017).

2009. Extracto de la exposición en Seminario "Filosofía Política en América Latina Hoy", Tercera parte. 5. La transmodernidad: 
la quinta edad del mundo. Doctorado de Estudios Culturales Latinoamericanos. Universidad Andina Simón Bolívar. Sede Ecuador. Publicado el 11 de mayo de 2015. En: https://www. youtube.com/watch?v=gql9yYhdvws (última visita 29 de noviembre de 2017).

Esponera Cerdán, Alfonso. O.P. 2010. B. de las Casas y la esclavización de los negros, según las aportaciones de I. Pérez Fernández O.P. En: Biblioteca Cervantes Virtual: http://www.cervantesvirtual.com/obra-visor/b-de-las-casas$y$-la-esclavizacin-de-los-negros-segn-las-aportacionesde-i-prez-fernndez-o-p-0/html/04651a3d-6767-4cd6-80e5489c70cf4fec_5.html (última consulta 28 de enero de 2019).

Faletto, Enzo. 2015. De la teoría de la dependencia al proyecto neoliberal. El caso chileno. En: Benavides Navarro, Leopoldo, Godoy Orellana, Milton y Vergara Edwards, Francisco (editores). Antología del pensamiento crítico chileno contemporáneo. Buenos Aires: CLACSO: 217-232.

Garay Montañez, Nilda. 2016. Reflexiones sobre las contribuciones del pensamiento decolonial en la enseñanza del derecho constitucional. En: Pensamiento Constitucional. 21: 81-105.

Gargarella, Roberto y Courtis, Christian. 2009. El nuevo constitucionalismo latinoamericano: promesas e interrogantes. CEPAL-Series Políticas sociales 153. Santiago de Chile: CEPAL.

Gonzáles Mantilla, Gorki. 2015. Abogados y globalización en el Perú (1990-2014). En: Parlamento y Constitución. 17: 67-119.

Grez Tosso, Sergio. 2009. La ausencia de un poder constituyente democrático en la historia de Chile. En: Revista Izquierdas, 3, 5: 1-21.

Guevara Gil, Armando. 2001. Las causas estructurales de la pluralidad legal en el Perú. En: Defensoría del Pueblo. Antropología y Derecho. Rutas de encuentro y reflexión. I Conferencia de la Red Latinoamericana de Antropología Jurídica-Sección Perú. Iquitos: Defensoría del Pueblo: 7-27.

2014. ¿Cómo funciona el derecho de aguas a 3300 m.s.n.m.?. En: Derecho PUCP. 73: 397-410.

Hagino, Córa Hisae. 2012. O ensino jurídico em Portugal: um estudo de caso sobre a faculdade de direito da universidade de coimbra. En: Confluēncias, 12, 2: 178-192.

Honores, Renzo. 2003a. Un vistazo a la profesión legal: abogados y procuradores en Lima, 1550-1650. En: Luis Gonzáles Vale (coordinador). Actas y Estudios. XIII Congreso del Instituto Internacional de Historia del Derecho Indiano. San Juan, 21 al 25 de mayo de 2000. Asamblea Legislativa de Puerto Rico: San Juan.

2003b. La asistencia jurídica privada a los señores indígenas ante la Real Audiencia de Lima, 1552-1570. Ponencia presentada para el Congreso de Latin America Studies Association, Dallas, 27-29 de marzo del 2003. En: https://lasa.international. pitt.edu/Lasa2003/HonoresRenzo.pdf (última consulta 28 de enero de 2019).

Hurtado Pozo, José. 1979. La ley importada. Lima: Centro de Estudios Derecho y Sociedad. En: https://www.unifr.ch/ddp1/derechopenal/ obrasjuridicas/oj_20080609_02.pdf (última consulta 30 de enero de 2019).

Instituto Nacional de Estadística e Informática (INEI). 2010. II Censo Nacional Universitario. Principales resultados. En: http://blog.pucp. edu.pe/media/835/20110202-II\%20CNU\%20 2010.pdf (última consulta 23 de mayo de 2013).

Leiva, Alberto David. 2010. La profesión legal en la obra de Juan de Matienzo (1520-1579). En: Revista Chilena de Historia del Derecho. 22, Tomo I: 435-444.

Levaggi, Abelardo. 2009. Tomás Jofré. Introductor de Giuseppe Chiovenda en el Derecho argentino. En: Revista Electrónica del Instituto de Investigaciones „Ambrosio L. Gioja“. III. 4: 98:106.

Lohmann Villena, Guillermo. 1969. El licenciado Diego Álvarez. En: Revista chilena de Historia del Derecho. 5: 45-53.

Manacés Valverde, Jesús y Gómez Calleja, Carmen. 2013. La verdad de Bagua. Informe en minoría de la comisión especial para investigar y analizar los sucesos de Bagua. Lima: Comisión de Derechos Humanos COMISEDH e Instituto de Defensa Legal - IDL.

Mantilla Falcón, Julissa. 2013. La importancia de la aplicación del enfoque de género al derecho: asumiendo retos. En: Themis. Revista de Derecho. Segunda Época. 63: 131-146.

Marzal, Manuel. 1981. Sociedades indígenas y nueva constitución. En: Derecho PUCP, 35: 109-115.

Meini, Iván. 2016. ¿Es posible hablar de error? El error culturalmente condicionado en el Perú. Felice Villavicencio versuns Iván Meini. En: Themis. Revista de Derecho. 68: 53-59.

Merino Acuña, Roger. 2008. ¿Recepción o resistencia? Americanización y Análisis Económico del Derecho en el Perú. En: The 
Cardozo Electronic Law Bulletin. 14. En: http://www.jus.unitn.it/ cardozo/Review/2008/Acuna.pdf (última consulta 30 de enero de 2019).

Mignolo, Walter. 2009. La idea de América Latina (la derecha, la izquierda y la opción decolonial). En: Crítica y Emancipación, primer semestre 2009, 2: 251-276.

Mignolo, Walter. 2012. Who speaks for the „Human“ in Human Rigths?. En: Barreto, José-Manuel (ed.). Human Rights from a Thrid World Perspective: Critique, History and International Law. Cambrigde Scholars. Cambridge: 44-64.

Montoya Vargas, Juny. 2011. Educación jurídica en América Latina: dificultades curriculares para promover los temas de interés público y de justicia social. En: El Otro Derecho. 38: 29-42.

Mujica, Jaris. 2011. Micropolíticas de la corrupción. Redes de poder y corrupción en el Palacio de Justicia. Lima: Asamblea Nacional de Rectores.

Noguera Fernández, Albert y Navas Alvear, Marco. 2016. Los nuevos derechos de participación en Ecuador ¿derechos constituyentes o derechos constitucionales?. Estudio del modelo constitucional de 2008. Valencia: Tirant lo blanch.

Olivero Pacheco, Nora. 1988. El Derecho Precolombino y el Derecho Indiano y las invasiones de tierra. En: Derecho PUCP 42: 101-122.

Pásara, Luis. 2004. La enseñanza del derecho en el Perú: su impacto sobre la administración de justicia. Lima: Ministerio de Justicia.

2005. Los abogados de Lima en la administración de justicia. Una aproximación preliminar. Lima: Consorcio Justicia Viva.

Pereyra, Osvaldo. 2018. Reseña de De Dios, S. (2016). Estudios sobre Jurisprudencia y juristas en la Corona de Castilla (siglos XV-XVII). Junta de Castilla y León. Valladolid. En: Magallánica, Revista de Historia Moderna: 4/8: 252-260.

Perez Lledó, Juan Antonio. 2007. Teoría y práctica en la enseñanza del Derecho. En: Revista sobre enseñanza del Derecho. 5, 9: 85-189.

Pérez Pérdomo, Rogelio. 2009. Desafíos de la educación jurídica latinoamericana en tiempos de globalización. En: El Otro Derecho. 38: 11-27.

Quijano, Aníbal. 1992. Colonialidad y Modernidad/Racionalidad. En: Perú Indígena 13 (29): 11-20.

2000. Colonialidad del poder, eurocentrismo y América Latina. En: Lander, Edgardo (compilador). La colonialidad del saber: eurocentrismo y ciencias sociales. Perspectivas latinoamericanas: 122-151.

2007. Colonialidad del poder y clasificación social. En: Santiago Castro-Gómez y Ramón Grosfoguel (editores).
El giro decolonial. Reflexiones para una diversidad epistémica más allá del capitalismo global. Bogotá: Siglo del Hombre Editores, Universidad Central, Instituto de Estudios Sociales Contemporáneos y Pontificia Universidad Javeriana, Instituto Pensar: 93-125.

Quijano, Aníbal y Wallerstein, Immanuel. 1992. La americanidad como concepto, o América en el moderno sistema mundial. En: Revista internacional de ciencias sociales. América: 1492-1992. Trayectorias históricas y elementos del desarrollo. UNESCO. 13: diciembre 1992: 583-592

Quiñones Oré, Hector Daniel. 2018. Etnografía de la corrupción de abogados de Lima. Tesis para optar el Grado de Magíster en Antropología. Universidad Nacional Mayor de San Marcos.

Ramos Nuñez, Carlos. 2005. Historia del Derecho Civil Peruano. Siglos XIX y XX. Tomo II: La codificación del siglo XIX: Los códigos de la Confederación y el Código Civil de 1852, primera reimpresión. Lima: Fondo Editorial de la Pontificia Universidad Católica del Perú.

2011. Historia del Derecho Civil Peruano. Siglos XIX y XX. Tomo VI: El Código de 1936. Volumen 3: El bosque institucional. E-book. Lima: Fondo Editorial de la Pontificia Universidad Católica del Perú.

2018. La letra de la ley. Historia de las constituciones del Perú. Lima: Centro de Estudios Constitucionales. Tribunal Constitucional.

Red de Universidades para la Prevención De Conflictos. 2017. Diagnóstico de la producción académica y experiencias de participación de universidades en espacios de diálogo y prevención de conflictos. Programa de las Naciones Unidas para el Desarrollo, Global Affairs Canada. En: http://cdn01. pucp.education/carc/wpcontent/uploads/2017/12/05130524/estudio_ universidades.pdf (última consulta 31 de enero de 2019).

Rubio Correa, Marcial. 2011. El sistema jurídico. Introducción al Derecho. Décima edición. Segunda reimpresión. Lima: Fondo Editorial de la Pontificia Universidad Católica del Perú. 
Santos, Boaventura de Sousa. 2006. De lo posmoderno a lo colonial, y más allá de ambos. En: Conocer desde el Sur. Para una cultura política emancipatoria. Fondo Editorial de la Facultad de Ciencias Sociales, Universidad Nacional Mayor de San Marcos y Programa de Estudios sobre Democracia y Transformación Global: 35-64.

Santos, Boaventura de Sousa. 2012. ¿Puede el derecho se emancipatorio? En: Derecho y emancipación. Serie Pensamiento jurídico contemporáneo 2. Corte Constitucional para el período de transición. Quito: 61-145.

Santos, Boaventura de Sousa. 2017. Más allá del pensamiento abisal: de las líneas globale a las ecologías de los saberes. En: Justicia entre saberes: Epistemologías del Sur contra el epistemicidio. Morata: 159-177.

Santos, Boaventura de Sousa. 2018. Introducción a las Epistemologías del Sur. En: Meneses, María Paula y Bidaseca, Karina (compiladoras). Epistemologías del Sur. Centro de Estudios Sociales, Universidad de Coimbra y CLACSO, Buenos Aires: 25-61.
Said, Edward W. 1979. Orientalism. Vintage Books. Nueva York Szemiński, Jan. 2015. “¿Quién tiene la razón: Don Phelipe Guama Poma de Ayala u otros cronistas en sus descripciones de las agencias de gobierno inca?". Revista Andina, 53: 19 - 43.

Villanueva Flores, Rocío. 1997. "Análisis del Derecho y perspectiva de género". En Derecho PUCP, número 51: 485-518.

Walsh, Catherine. 2007. Interculturalidad y colonialidad del poder. Un pensamiento y posicionamiento "otro" desde la diferencia colonial. En: Santiago Castro-Gómez y Ramón Grosfoguel (editores). El giro decolonial. Reflexiones para una diversidad epistémica más allá del capitalismo global. Bogotá: Siglo del Hombre Editores, Universidad Central, Instituto de Estudios Sociales Contemporáneos y Pontificia Universidad Javeriana, Instituto Pensar: 47-62.

Walsh, Catherine. 2010. Presentación. En: http://catherinewalsh.blogspot.de/search/label/PRESENTACIÓN\%20\%2F\%20 PRESENTATION (última consulta 24 de noviembre de 2017).

Whippie, Pablo. 2016. Guerra a los abogados. La defensa libre y los debates sobre el monopolio de los abogados y la corrupción de la justicia peruana, 1841-1862. En: Rosenmüler, Christoph y Ruderer, Stephan (eds.). "Dávidas, dones y dineros". Aportes a una nueva historia de la corrupción en América Latina desde el imperio español a la modernidad. Iberoamerikanisches Institut: Madrid/Frankfurt: 128-146. 